\title{
Preparation and Structural Characterization of Hybrid Composites of Semiconductor Oxides with Amorphous Carbon
}

\author{
Gabriela D.C. Zocolaro ${ }^{a}$, Gisele S. Silveira ${ }^{b}$, Marcos A.L. Nobre ${ }^{c}$, \\ Silvania Lanfredi ${ }^{d}$ \\ Laboratório de Compósitos e Cerâmicas Funcionais- LaCCeF, Faculdade de Ciências e \\ Tecnologia - FCT, Univ Estadual Paulista - UNESP, P.O Box 467, CEP 19060-900, \\ Presidente Prudente-SP, Brazil \\ agabi_dc_zocco@hotmail.com, ${ }^{b}$ gss.quimica@gmail.com, ${ }^{c}$ nobremal@fct.unesp.br, \\ dsilvania@fct.unesp.br
}

Keywords: Hybrid composites, Amorphous Carbon, Semiconductor.

\begin{abstract}
Organic/inorganic hybrids composites type have been reported as an alternative for the preparation of multifunctional materials with superior properties to those of individual constituents. In this work, hybrid composites of semiconductor oxides with amorphous carbon $(\mathrm{C} / \mathrm{ZnO}$ and $\mathrm{C} / \mathrm{TiO}_{2}$ ) were synthesized by partial pyrolysis method and characterized by X-ray diffraction (XRD), infrared spectroscopy (FTIR) and scanning electron microscopy (SEM). The XRD patterns showed the presence of crystalline diffraction lines overlaid by diffraction halos. Infrared spectra showed bands associated to the stretching of $\mathrm{Zn}-\mathrm{O}$ and Ti-O bonds, as well as bands assigned to the stretching vibrations of $\mathrm{C}-\mathrm{O}, \mathrm{C}=\mathrm{O}$ and $\mathrm{C}-\mathrm{H}$. Micrographs showed the formation of organized structures in the shape of plates and agglomerates of particles. Structural characterizations showed that the composites present the characteristics of the pristine semiconductors as well of the amorphous carbon matrix, showing a great synergism between $\mathrm{C} /$ semiconductor.
\end{abstract}

\section{Introduction}

Advanced chemical processes produce materials with different physical properties in relation to the conventional materials [1-3]. In this sense, the combination of organic and inorganic components in composites is presented as an alternative to the production of new multifunctional materials with a wide range of applications such as electronic and optical devices, biomaterials, membranes, coatings, flame-retardants, catalysts and photocatalysis [2-9].

Organic/inorganic composites are of great interest because of their mechanical, optical and thermal properties, which combine thermal and chemical stability of the ceramic materials with the processability of the polymeric organic materials $[2,10]$. Among the components of these materials can stand out polymers, carbon nanotubes, graphene, amorphous carbon, metal oxides, clays, silica, siloxanes, etc. [2-9].

Generally, organic/inorganic composites may be prepared in three ways. The first way is by the physical incorporation of the constituents, while the second one is through chemical bonds between the components. In this case are highlighted the hybrids which have covalent bonds between organic and inorganic components. The third class of hybrid materials is based on a combination of the two types of interaction previously described $[2,3,10]$.

In this sense, the present study aimed the preparation and the structural characterization of hybrid composites of semiconductors oxides with amorphous carbon, from the partial pyrolysis method $[6,7]$.

\section{Experimental}

Synthesis

$\mathrm{C} / \mathrm{ZnO}$ and $\mathrm{C} / \mathrm{TiO}_{2}$ hybrid composites were prepared by partial pyrolysis method, similar to the process developed by the Pechini method. The method consists in formation of a polymeric resin produced by the polyesterification of metal chelates with hydroxycarboxylic acids and a 
polyhydroxy alcohol such as ethylene glycol $[6,7,11,12]$. The starting reagents used were $\mathrm{ZnO}$, $\mathrm{TiO}_{2}$, citric acid $\left(\mathrm{C}_{6} \mathrm{H}_{8} \mathrm{O}_{7} . \mathrm{H}_{2} \mathrm{O}\right)$ and ethylene glycol $\left(\mathrm{HOCH}_{2} \mathrm{CH}_{2} \mathrm{OH}\right)$. Citric acid was solubilized in ethylene glycol (mass ratio of 40:60) with continuous magnetic stirring at $70^{\circ} \mathrm{C}$, to promote the polyesterification. After the polyesterification reaction, a polymeric gel was formed and the oxide was gradually added. The resulting material was maintained in a beaker and subjected to a primary calcination in a box-type furnace. The calcination was performed in a single step in static air atmosphere from room temperature to $300{ }^{\circ} \mathrm{C}$ with a heating rate of $1{ }^{\circ} \mathrm{C} / \mathrm{min}$. The material obtained was deagglomerated in agate mortar with a 325- mesh minimum, obtaining the composites termed $\mathrm{C} / \mathrm{ZnO}$ and $\mathrm{C} / \mathrm{TiO}_{2}$. The same procedure was used to synthesize the amorphous carbon.

\section{Characterization}

Structural characterization of the $\mathrm{C} / \mathrm{ZnO}$ and $\mathrm{C} / \mathrm{TiO}_{2}$ composites was carried out by X-ray diffraction using a Shimadzu diffractometer (XRD-6000 model) with $\mathrm{Cu}$ Ka radiation $(\lambda=1.54060)$ and a graphite monochromator in the range of $5^{\circ} \leq 2 \theta \leq 80^{\circ}$ with a scan step of $0.02^{\circ}$ and a fixed counting time of $0.6 \mathrm{~s}$. Divergence, scattered and receiving radiation slits were $1^{\circ}, 1^{\circ}$ and $0.3 \mathrm{~mm}$, respectively. The analysis of chemical bonds was performed by infrared spectroscopy. Samples were diluted in $\mathrm{KBr}$ in the ratio $1: 100$ and pressed into pellet form. The measurements were performed in the region of 4000-400 $\mathrm{cm}^{-1}$ with resolution of $8 \mathrm{~cm}^{-1}$ and 100 scans, using an infrared spectrometer Shimadzu (IR Affinity model). The analysis of the microstructure of materials was performed by scanning electron microscopy (SEM) using a microscope Carls Zeiss EVO LS15 model, operating at $30 \mathrm{kV}$ on samples coated with a thin gold film.

\section{Results and Discussion}

Fig. 1 shows the XRD pattern of the $\mathrm{TiO}_{2}$ and $\mathrm{ZnO}$ oxides, amorphous carbon and of the $\mathrm{C} / \mathrm{ZnO}$ and $\mathrm{C} / \mathrm{TiO}_{2}$ composites.
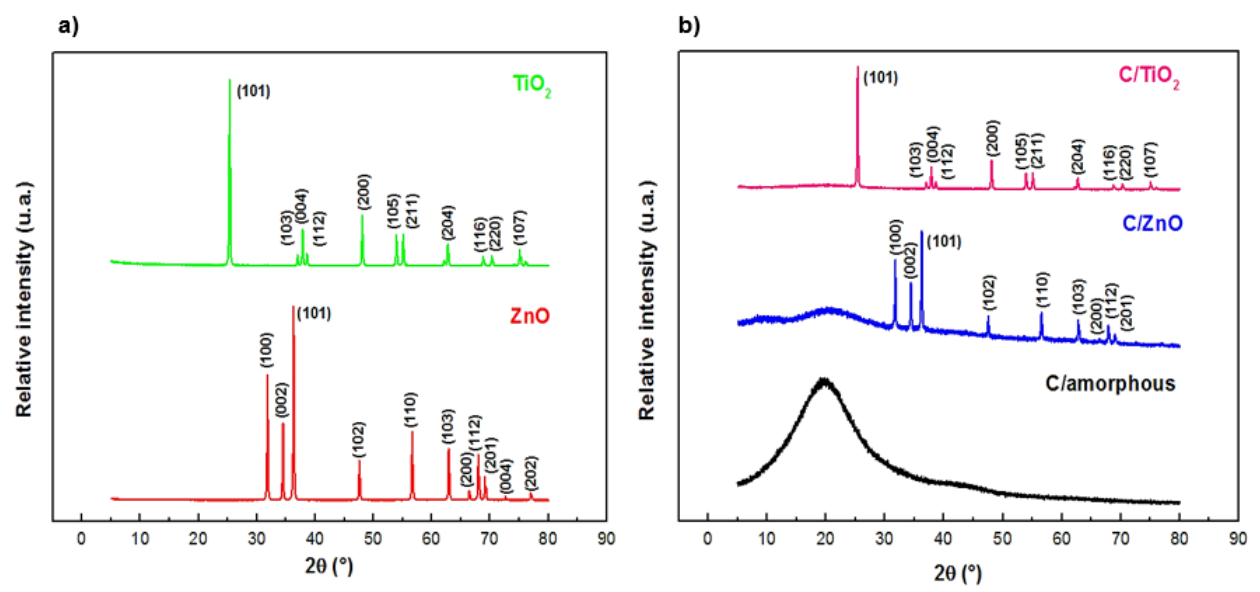

Fig. 1. X-ray diffractogram of a) $\mathrm{ZnO}$ and $\mathrm{TiO}_{2}$, b) $\mathrm{C} /$ amorphous, $\mathrm{C} / \mathrm{ZnO}$ and $\mathrm{C} / \mathrm{TiO}_{2}$.

According to Fig. 1, the composites obtained present diffraction lines overlapped by halos of the amorphous carbon matrix. For the $\mathrm{C} / \mathrm{TiO}_{2}$ composite is observed essentially the presence of crystalline diffraction lines. The presence of the amorphous carbon matrix can be observed only by the reduction of the diffraction lines as well as by small variations in the background of diffraction pattern. This behavior can be associated with the synthesis process of the composites. The partial pyrolysis synthesis is based on the Pechini method where during the pyrolysis step of the polymeric resin, the metal acts as a lattice former suffering oxidation during the burning of organic matter for formation of crystallites [11,12]. In this sense, the formation of $\mathrm{TiO}_{2}$ can be more favored than $\mathrm{ZnO}$, which can explain the higher burning of organic matter in this composite. The crystalline diffraction lines observed for the $\mathrm{C} / \mathrm{ZnO}$ composite correspond to $\mathrm{ZnO}$ phase with hexagonal symmetry and space group P63mc (JCPDS 36-14-51 card) [13]. For the $\mathrm{C} / \mathrm{TiO}_{2}$ composite, the diffraction lines observed are attributed to the $\mathrm{TiO}_{2}$ anatase with tetragonal symmetry and space 
group I41/amd (JCPDS 22-1272 card) [13]. The diffractogram profiles obtained for the amorphous carbon matrix and for the $\mathrm{C} / \mathrm{ZnO}$ composite indicate that these matrices have a random type structure, consisting of two different carbon species [14]. The first type consists in a graphite-like structure of short-range with micro crystallites. In terms of crystallinity, this structure is placed between graphite carbon and amorphous carbon, termed turbostratic or reticular random. The second species present in the material is the amorphous carbon, a kind of highly disordered carbon and non-aromatic type. The presence of these species in the carbon materials results in different contributions to the profile of the diffractograms. While amorphous carbon has small contribution to the diffractogram profile, only in the intensity of the background, the turbostratic specie is responsible by the presence of the halo in $2 \theta \approx 20^{\circ}$. This halo is associated with the interplanar spacing between the graphitic layers (La), that is associated with the plane (002) of the graphite structure. This parameter is of great importance in carbonaceous materials arising from pyrolysis since it can be related to the size of microcrystal graphite-type, which can be associated to the porosity of these materials [14-17]. This relation is established in the sense that the higher the parameter $(\mathrm{La})$ higher the porosity of material, which is of great relevance, for example, in the production of activated carbons [14-17].

The analysis of vibrational modes, characteristic of the chemical bonds, was carried out by infrared spectroscopy. Fig. 2 shows the spectra obtained for the powders of $\mathrm{ZnO}, \mathrm{TiO}_{2}$, $\mathrm{C}$ /amorphous, $\mathrm{C} / \mathrm{ZnO}$ and $\mathrm{C} / \mathrm{TiO}_{2}$.
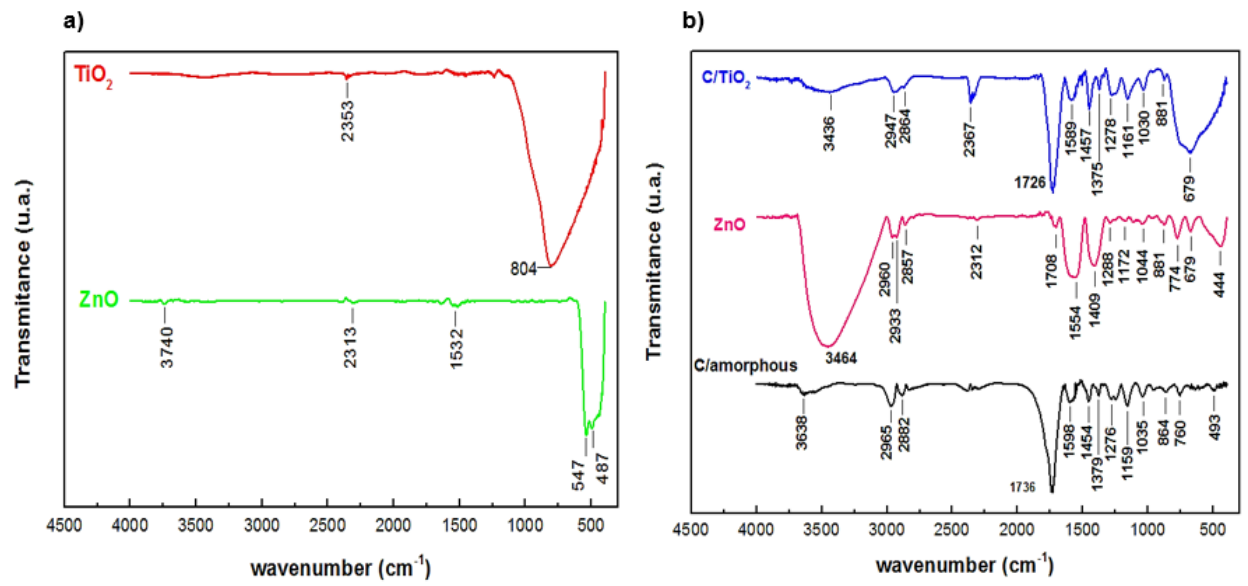

Fig. 2. FTIR spectra for: a) $\mathrm{ZnO}$ and $\mathrm{TiO}_{2}$, b) $\mathrm{C} /$ amorphous, $\mathrm{C} / \mathrm{ZnO}$ and $\mathrm{C} / \mathrm{TiO}_{2}$.

The $\mathrm{TiO}_{2}$ spectrum, Fig. 2 (a), shows an intense band at $804 \mathrm{~cm}^{-1}$ associated to the Ti-O bonds [19]. In $\mathrm{ZnO}$ spectrum, in the region between $547-487 \mathrm{~cm}^{-1}$ are observed two bands related with $\mathrm{Zn}-\mathrm{O}$ bonds in the basal and uniaxial planes of the wurtzite type structure. According to the literature these bonds have different lengths, being $1.9973 \dot{\mathrm{A}}$ and $1.992 \dot{\mathrm{A}}$ in the basal and uniaxial planes, respectively [20].

In Fig. 2 (b) the infrared spectra of the composites show broad and intense bands in the region between $3638-3436 \mathrm{~cm}^{-1}$ associated with the symmetrical stretching of hydroxyl groups $\left(\mathrm{OH}^{-}\right)[6,7,18]$. Deformation vibrational of the $\mathrm{OH}$ and $\mathrm{C}-\mathrm{H}$ groups are observed between 1598$1409 \mathrm{~cm}^{-1}[6,7,18]$. In the region between $2965-2864 \mathrm{~cm}^{-1}$ are shown bands assigned to the $\mathrm{C}-\mathrm{H}$ stretching $[6,7,18]$ related to the polyester formed during the polyesterification process of the materials. The spectra show still bands associated to the $\mathrm{C}=\mathrm{O}$ stretching between $1736-1708 \mathrm{~cm}^{-1}$ and bands attributed to the C-O stretching (1379-1030 $\left.\mathrm{cm}^{-1}\right)$ of esters related to the polyester formed during the polyesterification process $[6,7,18]$. Bands positioned in the region between $864-$ $760 \mathrm{~cm}^{-1}$ were assigned to the $\mathrm{C}-\mathrm{C}$ stretching which can be associated to the starting materials and the formation of polyester $[6,7,18]$. Bands in the range between $679-444 \mathrm{~cm}^{-1}$ are attributed to the metal-oxygen bonds of $\mathrm{Zn}-\mathrm{O}$ and Ti-O [19,20]. Table 1 lists the assignment of the absorption bands shown in the FTIR spectra of the Fig. 2. 
Table 1. Assignment of the FT-IR absorption bands of $\mathrm{ZnO}, \mathrm{TiO}_{2}, \mathrm{C} /$ amorphous,

$\mathrm{C} / \mathrm{ZnO}$ and $\mathrm{C} / \mathrm{TiO}_{2}$.

\begin{tabular}{ccc}
\hline Assignments & Wavenumber $\left(\mathbf{c m}^{-1}\right)$ & Reference \\
$v_{\text {sim }}(\mathrm{OH})$ water & $3740-3436$ & {$[6,17,18]$} \\
$v_{\text {sim }}(\mathrm{C}-\mathrm{H})$ & $2965-2864$ & {$[6,17,18]$} \\
$v_{\text {sim }}\left(\mathrm{CO}_{2}\right)$ & $2367-2313$ & {$[6,17,18]$} \\
$v_{\text {sim }}(\mathrm{C}=\mathrm{O})$ ester & $1736-1708$ & {$[6,17,18]$} \\
$\delta \mathrm{O}-\mathrm{H}, \delta_{\text {ass }} \mathrm{C}-\mathrm{H}$ & $1598-1409$ & {$[6,17,18]$} \\
$v(\mathrm{C}-\mathrm{O})$ ester, $\delta_{\text {sim }} \mathrm{C}-\mathrm{H}$ & $1379-1030$ & {$[6,17,18]$} \\
$v_{\text {sim }}(\mathrm{C}-\mathrm{C})$ & $864-760$ & {$[6,17,18]$} \\
Vibrations $\mathrm{M}-\mathrm{O} *$ & $679-444$ & {$[19,20]$} \\
\hline
\end{tabular}

* M represents the $\mathrm{Zn}$ or $\mathrm{Ti}$.

The morphology of the powders was investigated by scanning electron microscopy. For the analysis were used two types of detectors: secondary electrons (SE) and backscattered electrons (BSD). The first type of detector obtains images formed from the interaction of the electron beam with the sample by low-energy electrons. These electrons allow a high resolution of image and ensure a contrast associated mainly to topography of the sample. In the second type of detector the image is fundamentally obtained of the electron beam interactions with the sample from highenergy electrons that suffer an elastic collision with the sample surface. In this situation are reached large magnifications. However, it is possible to obtain information such as the topography of the sample (contrast function of the relief), as well as image of composition (contrast as a function of atomic number of the elements present in the sample) [21]. The micrographs obtained for the $\mathrm{ZnO}$ and $\mathrm{TiO}_{2}$ powders and for the $\mathrm{C}$ /amorphous, $\mathrm{C} / \mathrm{ZnO}$ and $\mathrm{C} / \mathrm{TiO}_{2}$ composites are shown in Fig. 3 and 4.
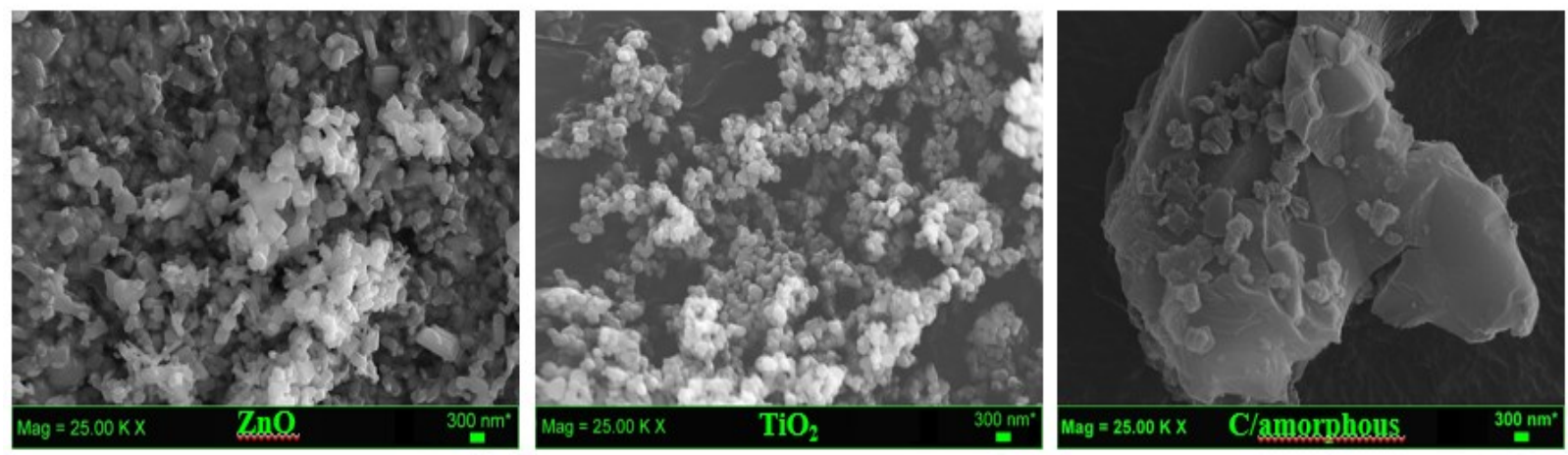

Fig. 3. Scanning electron microscopy (SEM) image of the $\mathrm{ZnO}, \mathrm{TiO}_{2}$ and $\mathrm{C} /$ amorphous using secondary electrons.
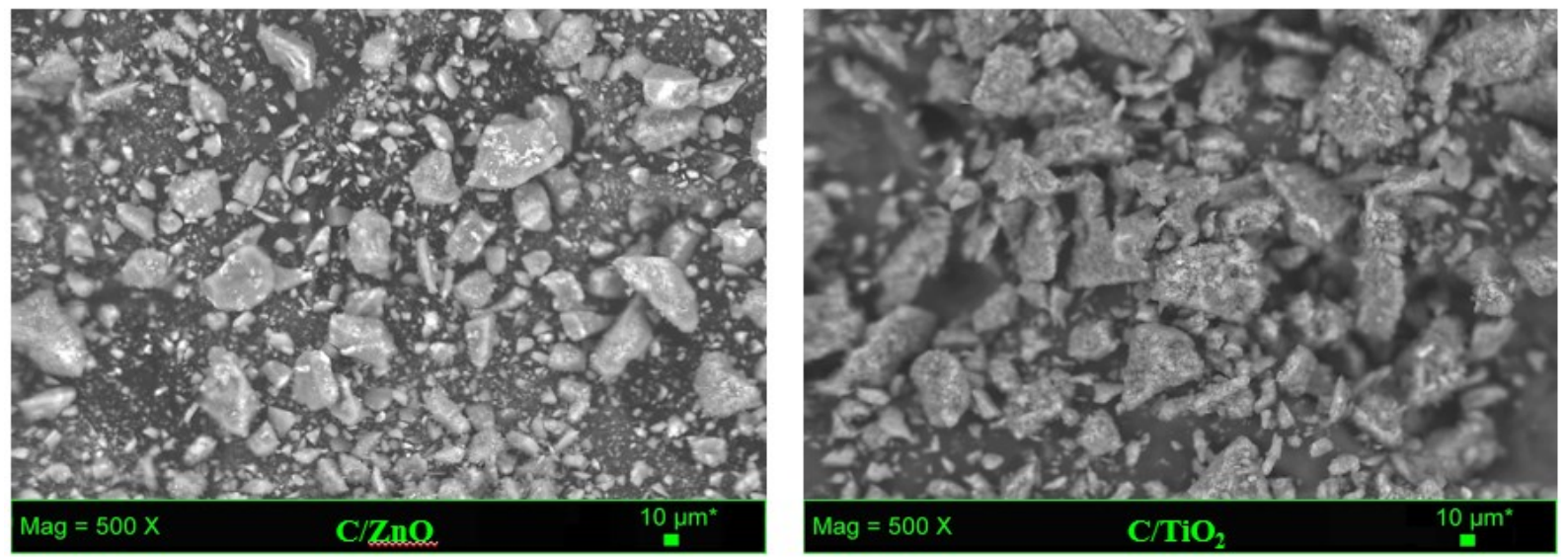

Fig. 4. Scanning electron microscopy (SEM) image of the $\mathrm{C} / \mathrm{ZnO}$ and $\mathrm{C} / \mathrm{TiO}_{2}$ composites using backscattered electrons. 
The micrographs of the $\mathrm{ZnO}$ and $\mathrm{TiO}_{2}$ powders (Fig. 3) show the presence of agglomerated particles of different sizes with spheroidal shape and of elongated bats $(\mathrm{ZnO})$. The average particle size, for the oxides, ranged between $87 \mathrm{~nm}-826 \mathrm{~nm}$. The micrograph obtained for the C/amorphous showed the presence of clusters of different sizes and shapes, constituting a matrix with high carbon content and organized in the shape of overlapping plates. Similar results were obtained for the composites shown in Fig. 4. Lower carbon content was observed for $\mathrm{C} / \mathrm{TiO}_{2}$ than $\mathrm{C} / \mathrm{ZnO}$ composite. These results are in according to X-ray diffraction data. The average agglomerate sizes for the composites ranged between $14 \mu \mathrm{m}$ and $90 \mu \mathrm{m}$.

\section{Conclusions}

The methodology used was suitable for preparation of $\mathrm{C} / \mathrm{ZnO}$ and $\mathrm{C} / \mathrm{TiO}_{2}$ hybrid composites. The structural characterizations showed the formation of hybrid composites by the combination of crystalline diffraction lines, associated to the semiconductor oxides, with the diffraction halos, characteristics of the organic matrix. The results are in according to the morphologic analysis of these materials, showing a synergism between the semiconductor and the amorphous carbon matrix.

\section{Acknowledgments}

The authors are grateful to the Brazilian research agencies: FAPESP, CNPq and UNESP/PROPe for financial support.

\section{References}

[1] P.G.P. Moraes, S. Lanfredi, J. Matos, M.A.L. Nobre, Photocatalytic Properties of a Hybrid Composite of $\mathrm{ZnO}$ with Amorphous Carbon Containing Homogeneous Dispersion of Zn Metallic. In: The Annual World Conference on Carbon, 2013, Rio de Janeiro. Carbon - Rio 2013. v. I.

[2] N.M. José, L.A.S.A. Prado: Quim. Nova Vol. 28 (2005), p. 281.

[3] A.C. Esteves, A.B. Timmons, T. Trindade: Quim. Nova Vol. 27 (2004), p. 798.

[4] L.B. Paiva, A.R. Morales, T.R. Guimarães: Ciência e Tecnologia Vol. 16 (2006), p. 136.

[5] A.H. Kalinke, A.J.G. Zarbin: Quim. Nova Vol. 37 (2014), p. 1289.

[6] S. Lanfredi, M.A.L. Nobre, P.G.P. Moraes, J. Matos: Ceram. Int. Vol. 40 (2014), p. 525

[7] S. Lanfredi, G.S. Silveira, B.S. Potensa, M.A.L. Nobre: MRS Advances (2015), p. 1.

[8] K. II Park, M. Lee, Y. Liu, S. Moon, G.T. Hwang, G. Zhu, J.E. Kim, S.O. Kim, D.K. Kim, Z.L. Wang, K.J. Lee: Adv. Mat. Vol. 24 (2012), p. 2999.

[9] J.E. Lee, S.H. Yu, D.J. Lee, D.C. Lee, S.I. Han, Y.E. Sung, T. Hyeon: Energy Environ. Sci. Vol. 5 (2012), p. 9528.

[10] P.W. Atkins, D.F. Shriver: Química Inorgânica. (Bookman 4. ed. Porto Alegre, 2008).

[11] M. Pechini. U. S. Patente, 3330697 (1997).

[12] M.A.L. Nobre. E. Longo, E.R. Leite, J.A. Varela: Mater. Lett. Vol. 28 (1996), p. 215.

[13] JCPDS - International Centre for Diffraction Data. PCPDFWIN v. 2.1. Copyright $C$ JCPDSICDD. 2000.

[14] L. Lu et. al.: Carbon. Vol. 39 (2001), p. 1821.

[15] T. Cordero, J. Rodríguez Mirasol, J. Bedia, J.J. Rodríguez: Opt. Pura Apl. Vol. 40 (2) (2007), p. 161.

[16] M.A. Schettino Jr., J.C.C. Freitas, A.G. Cunha, F.G. Emmerich, A.B. Soares, P.R.N. Silva: Quim. Nova Vol. 30 (2007), p. 1663.

[17] N. Yoshizawa, K. Maruyama, Y. Yamada, E. Ishikawa, M. Kobayashi, Y. Toda, M. Shiraishi: Fuel Vol. 81 (2002), p. 1717.

[18] R. Silverstein, F.X. Webster, D. Kiemle: Identificação Espectrométrica de Compostos Orgânicos. (LTC 7.ed. Rio de Janeiro, 2007). 
[19] R.A. Nyquist, R.O. Kagel: Infrared Spectra of Inorganic Compounds $\left(3800-45 \mathrm{~cm}^{-1}\right)$. (Academic Press Inc. 1997).

[20] T. Steiner: Semiconductor Nanostructures for Optoelectronic Applications. (Artech House Inc. Boston, 2004).

[21] A.B. Dedavid, C.I. Gomes, G. Machado, Microscopia eletrônica de varredura: aplicações e preparo de amostras: materiais poliméricos, metálicos e semicondutores, EDIPUCRS, Porto Alegre, 2007. 
Reproduced with permission of copyright owner. Further reproduction prohibited without permission. 